\title{
Manajemen Pemangkasan Tanaman Teh (Camellia sinensis (L.) O. Kuntze) di Unit Perkebunan Tambi, Jawa Tengah
}

\section{Pruning Management of Tea (Camellia sinensis (L.) O. Kuntze) at Tambi Plantation, Central Java}

\section{Ika Ari Safitri dan Ahmad Junaedi*}

Departemen Agronomi dan Hortikultura, Fakultas Pertanian, Institut Pertanian Bogor (Bogor Agricultural University), Jalan Meranti, Kampus IPB Dramaga, Bogor 16680, Indonesia Telp. \& Faks. 0251-8629353 e-mail: agronipb@indo.net.id *Penulis untuk korespondensi : junaedi_agr@yahoo.com

Disetujui 20 Agustus 2018 / Published online 3 September 2018

\begin{abstract}
Research has been carried out at Tambi Plantation, Wonosobo, Central Java from February until June 2017. The objective of this research are describing tea plant condition prior and after pruning, as well as technical and managerial aspect on pruning activity. Criterias for pruning are the plant height $>110 \mathrm{~cm}$, diameter of tea bush $\pm 120 \mathrm{~cm}$, and dorman buds percentage $>70 \%$. The observation during pruning were pruning height, pruning equipment, pruning type, broken branch percentage, pruning time, pruning field acreage, labor number and pruning capacity, and pruning rotation. Observation after pruning were new growth shoot. The observation on plant height before pruning was $<110 \mathrm{~cm}$ with $<120 \mathrm{~cm}$ of shoot diameter, and dormant buds more then $>70 \%$. The highest productivity was achieved at $3^{\text {rd }}$ year after pruning and decline at $4^{\text {th }}$ year. Pruning type in UP Tambi was "clean prunning" using sickle equipment. Pruning rotation in UP Tambi is 4 to 5 years. The broken brunches by prunning as observed to worker showed not to be affected by worker age and working duration.
\end{abstract}

Keywords: active buds, broken branch, dormant buds, pruning height, pruning litter

\begin{abstract}
ABSTRAK
Penelitian dilaksanakan di Unit Perkebunan Tambi, PT Tambi, Wonosobo, Jawa Tengah pada bulan Februari hingga Juni 2017. Penelitian bertujuan untuk mendeskripsikan kondisi tanaman teh pada waktu menjelang dan setelah pemangkasan, serta aspek teknis pelaksanaan dan pengelolaan pemangkasan. Kriteriakriteria sebelum dilaksanakan pemangkasan yaitu tinggi tanaman $>110 \mathrm{~cm}$, diameter bidang petik $\pm 120 \mathrm{~cm}$, dan persentase pucuk burung $>70 \%$. Pengamatan saat pemangkasan yaitu tinggi pangkasan, alat pangkas, tipe/jenis pangkasan, persentase kerusakan cabang, waktu pemangkasan, luas areal pangkasan, jumlah tenaga kerja dan kapasitas pemangkas, serta daur/gilir pangkasan. Pengamatan setelah pemangkasan yaitu pertumbuhan tunas baru. Hasil pengamatan tinggi tanaman sebelum pemangkasan adalah $<110 \mathrm{~cm}$ dengan diameter bidang petik $<120 \mathrm{~cm}$, dan persentase pucuk burung $>70 \%$. Produktivitas tertinggi dicapai pada tahun pangkas III dan menurun pada tahun pangkas IV. Tipe atau jenis pangkasan yang dilakukan di UP Tambi adalah pemangkasan bersih menggunakan sabit pangkas. Gilir pangkas di UP Tambi adalah 4-5 tahun. Kerusakan cabang akibat pemangkasan tidak dipengaruhi oleh lama bekerja dan usia tenaga kerja.
\end{abstract}

Kata kunci: kerusakan cabang, pucuk burung, pucuk peko, serasah hasil pangkasan, tinggi pangkasan 


\section{PENDAHULUAN}

Tanaman teh (Camellia sinensis (L.) O. Kuntze) merupakan salah satu jenis tanaman dari keluarga Theaceae yang memiliki banyak manfaat kesehatan, diantaranya anti obesitas dan anti alergi (Martono dan Setiyono, 2014). Teh merupakan salah satu minuman yang banyak dikonsumsi oleh masyarakat lokal maupun luar negeri. Hal ini dikarenakan teh mempunyai rasa dan aroma yang khas. Syarat tumbuh optimal tanaman teh adalah suhu $13-15{ }^{\circ} \mathrm{C}$ dengan kelembaban relatif $>70 \%$. Ketinggian tempat yang baik untuk pertumbuhan tanaman teh adalah 400-2.000 meter di atas permukaan laut (Effendi et al., 2010). Curah hujan optimum untuk tanaman teh adalah 223$417 \mathrm{~mm}$ bulan $^{-1}$ (Supriadi dan Rokhmah, 2014). Komoditas teh merupakan salah satu komoditas perkebunan unggulan di Indonesia. Indonesia adalah negara pengekspor teh terbesar kedua setelah Vietnam untuk kawasan ASEAN yaitu $32,13 \%$ dari total produksi teh ASEAN, sedangkan produksi Vietnam 43,48\% (PDSIP, 2015). Tenaga kerja sangat dibutuhkan untuk menghasilkan produksi yang banyak, khususnya tenaga kerja pemetikan (Helmayanti, 2011).

Produksi teh di Indonesia tahun 2009 hingga 2013 berturut-turut adalah 75.451, $73.524,65.144,59.351$, dan 58.814 ton. Produksi teh yang mengalami penurunan tersebut dipengaruhi oleh luas areal produksi yang juga menurun. Luas areal produksi teh pada tahun 2010 hingga 2013 berturut-turut adalah 38.750, 38.609, 38.103, dan 37.922 ha (SPI, 2014). Produktivitas teh di Indonesia berfluktuatif pada tahun 20032014. Produktivitas teh nasional tertinggi terjadi pada tahun 2009 yaitu $1.571 \mathrm{~kg} \mathrm{ha}^{-1}$. Hasil produktivitas tersebut masih tergolong rendah dibandingkan dengan produktivitas negara penghasil teh lainnya, seperti Malaysia yang mencapai $6.501 \mathrm{~kg} \mathrm{ha}^{-1}$ (PDSIP, 2015).

Budi daya tanaman teh bertujuan untuk mendapatkan hasil panen berupa pucuk atau daun muda. Pucuk yang berkualitas adalah pucuk peko. Salah satu cara untuk memacu pertumbuhan pucuk adalah pemangkasan. Pemangkasan merupakan kegiatan pemeliharaan tanaman teh membentuk perdu yang bertujuan untuk membuang cabangcabang yang kurang produktif, mempertahankan kondisi bidang petik tetap rendah dan rata, sehingga memudahkan pemetikan dan mempertahankan pertumbuhan pada fase vegetatif (Setyamidjaja, 2000). Serasah hasil pangkasan biasanya berupa daun, cabang, dan ranting. Serasah hasil pangkasan diletakkan di atas luka pangkas. Jika serasah hasil pangkasan sudah kering, maka harus diturunkan ke tanah untuk menekan pertumbuhan gulma, menjaga kelembaban tanah, menahan erosi, dan sebagai bahan organik tanah
(Enomoto, 2013). Selain serasah hasil pangkasan, lumut yang tumbuh di cabang dan batang harus dibersihkan agar tidak mengganggu pertumbuhan tunas baru (Effendi et al., 2010).

Kriteria tanaman teh yang dipangkas adalah tinggi bidang petik > $110 \mathrm{~cm}$, produktivitas menurun, dan pucuk burung > $70 \%$. Kegiatan pemangkasan membutuhkan pengelolaan yang baik untuk menghindari kerusakan yang banyak akibat pemangkasan. Keberhasilan pemangkasan dipengaruhi oleh jenis, waktu pemangkasan, daur atau gilir pangkas, cara pemangkasan, dan kemahiran pemangkas (Puslitbun, 1997). Penelitian ini secara umum bertujuan untuk meningkatkan pengetahuan, pengalaman, dan kemampuan profesional penulis dalam mengelola perkebunan teh yang diperoleh dari lapangan. Topik khusus penelitian ini adalah mempelajari pemangkasan tanaman teh.

\section{METODE}

Kegiatan penelitian dilaksanakan di Unit Perkebunan Tambi, Wonosobo, Jawa Tengah, pada bulan Februari hingga bulan Juni 2017. Pengamatan data primer meliputi pengamatan sebelum, saat, dan setelah pemangkasan. Pengamatan tersebut dilakukan di Unit Perkebunan (UP) Tambi pada tanaman yang dipangkas bulan Februari 2017 serta pada blok yang memasuki daur atau gilir pangkas yang berbeda. Pengamatan dilakukan di Blok Taman, Blok Pemandangan 1, dan Blok Tanah Hijau yang memiliki ketinggian tempat berbeda dan klon yang berbeda (Blok Taman dan Blok Pemandangan 1 memiliki klon Gambung 4, sedangkan Blok Tanah Hijau adalah Seedling). Blok Taman memiliki ketinggian tempat 1.415$1.600 \mathrm{~m}$ dpl, Blok Pemandangan 1 1.700-2.150 m dpl, dan Blok Tanah Hijau 1.225-1.490 m dpl. Setiap blok terdapat satu nomor kebun dan setiap nomor kebun terdapat 11 tanaman contoh. Pengumpulan data yang dilakukan oleh penulis meliputi data primer dan data sekunder. Data primer mencakup topik khusus pemangkasan teh yang diperoleh melalui pengamatan langsung di lapangan, wawancara dengan karyawan, dan dokumentasi. Data primer terdiri atas pengamatan sebelum pemangkasan, saat pemangkasan, dan setelah pemangkasan. Pengamatan sebelum pemangkasan meliputi: tinggi tanaman dan diameter bidang petik, persentase pucuk burung, dan pencatatan produktivitas tahun sebelumnya. Pengamatan saat pemangkasan meliputi: tinggi pangkasan, alat pangkas, tipe/jenis pangkasan, persentase kerusakan cabang akibat pemangkasan, waktu pemangkasan, luas areal pangkasan, jumlah tenaga kerja dan kapasitas pemangkas, serta 
daur/gilir pangkasan. Pengamatan setelah pemangkasan adalah pertumbuhan tunas baru. Data sekunder diperoleh dari data yang dimiliki perusahaan. Data tersebut antara lain: sejarah perusahaan, letak geografis atau letak wilayah administratif, keadaan iklim dan tanah, luas areal konsesi dan tata guna lahan, keadaan tanaman dan produksi, struktur organisasi dan ketenagakerjaan, data curah hujan 10 tahun terakhir, serta peta kebun Unit Perkebunan Tambi tahun 2017.

Data yang diperoleh dianalisis secara kualitatif dan kuantitatif. Analisis kualitatif dilakukan dengan metode deskriptif, sedangkan analisis kuantitatif dilakukan dengan mencari ratarata, persentase, uji beda nyata terkecil (BNT) atau least significant difference (LSD), dan uji $t$ student dengan taraf $\alpha=5 \%$. Hasil pengamatan dibandingkan dengan rencana yang telah dibuat atau literatur. Nilai berbeda nyata apabila $t-$ hitung $>\mathrm{t}$-tabel dan tidak berbeda nyata apabila thitung $<\mathrm{t}$-tabel. T-tabel diperoleh dari nilai sebaran t pada taraf $\alpha=5 \%$ dan db $\left(\mathrm{n}_{1}+\mathrm{n}_{2}-2\right)$. Uji
BNT, angka yang diikuti huruf yang sama tidak berbeda nyata pada taraf $\alpha=5 \%$ dan angka yang diikuti huruf yang tidak sama berbeda nyata pada $\operatorname{taraf} \alpha=5 \%$ (Riduwan dan Sunarto, 2011).

\section{HASIL DAN PEMBAHASAN}

\section{Pengamatan Sebelum Pemangkasan}

Pemangkasan teh merupakan salah satu tindakan kultur teknis dalam pengelolaan kebun teh dengan tujuan untuk menjaga, meningkatkan produksi, produktivitas, dan mutu (Rusmana, 2000). Kegiatan pengamatan sebelum pemangkasan meliputi : tinggi tanaman, diameter bidang petik, persentase pucuk burung, dan produktivitas tahun sebelumnya (2016).

\section{Tinggi Tanaman dan Diameter Bidang Petik}

Tinggi tanaman dan diameter bidang petik adalah kriteria sebelum dilaksanakan pemangkasan tanaman teh. Tabel pengamatan tinggi tanaman dan diameter bidang petik sebelum pemangkasan dapat dilihat pada Tabel 1 .

Tabel 1. Tinggi tanaman dan diameter bidang petik sebelum pemangkasan

\begin{tabular}{lccccc}
\hline \multicolumn{1}{c}{ Blok } & Nomor Kebun & $\mathrm{n}$ & $\begin{array}{c}\text { Umur } \\
\text { Pangkas } \\
\text { (tahun) }\end{array}$ & $\begin{array}{c}\text { Tinggi Tanaman } \\
(\mathrm{cm})\end{array}$ & $\begin{array}{c}\text { Diameter bidang } \\
\text { petik }(\mathrm{cm})\end{array}$ \\
\hline Taman & 15 & 11 & 4 & $92,55 \pm 3,08 \mathrm{~b}$ & $105,30 \pm 40,10 \mathrm{a}$ \\
Pemandangan 1 & 1 & 11 & 5 & $96,55 \pm 5,77 \mathrm{~b}$ & $106,70 \pm 30,20 \mathrm{a}$ \\
Tanam hijau & 8 & 11 & 5 & $101,45 \pm 6,06 \mathrm{a}$ & $127,00 \pm 31,00 \mathrm{a}$ \\
\hline Rata-rata & & & & $96,85 \pm 4,97$ & $113,00 \pm 33,77$ \\
\hline
\end{tabular}

Keterangan: Angka yang diikuti huruf yang sama tidak berbeda nyata pada taraf $\alpha=5 \%$, n: jumlah tanaman contoh

Kriteria tanaman teh yang dipangkas adalah tinggi tanaman atau bidang petik $110 \mathrm{~cm}$ (Puslitbun, 1997). Apabila ketinggian bidang petik $>110 \mathrm{~cm}$ akan menyulitkan para pemetik. Hasil pengamatan pada Tabel 1 menunjukkan bahwa tinggi tanaman Blok Taman tidak berbeda nyata dengan Blok Pemandangan 1, serta tinggi tanaman Blok Taman dan Blok Pemandangan 1 berbeda nyata dengan Blok Tanah Hijau. Ratarata tinggi tanaman sebelum dipangkas adalah $96,85 \mathrm{~cm}$. Berdasarkan kriteria tinggi tanaman, tanaman teh di Blok Taman, Blok Pemandangan 1, dan Blok Tanah Hijau belum saatnya dipangkas karena tidak begitu menyulitkan para pemetik. Hal itu dikarenakan ketinggian ketiga blok tersebut $>1.200 \mathrm{~m} \mathrm{dpl}$, sehingga memang telah memasuki daur atau gilir pangkasnya yaitu 4-5 tahun (PPTK, 2006). Selain itu, semakin tua umur pangkas, maka akan semakin tinggi tanaman. Berdasarkan pengamatan, Blok Taman yang memiliki umur pangkas 4 tahun, tinggi tanamannya lebih rendah daripada Blok Pemandangan 1 dan Blok Tanah Hijau yang memiliki umur pangkas 5 tahun. Berdasarkan pengamatan pada Tabel 1, diameter bidang petik ketiga blok tidak berbeda nyata. Rata-rata diameter bidang petik sebesar $113 \mathrm{~cm}$. Diameter bidang petik standar yang diterapkan di UP Tambi adalah $\pm 120 \mathrm{~cm}$. Hal tersebut menunjukkan kerapatan tanaman di UP Tambi tidak begitu rapat, sehingga memudahkan pemetik dalam pengambilan pucuk teh di kebun.

\section{Persentase Pucuk Burung}

Pucuk burung merupakan pucuk yang sedang dalam keadaan dorman. Semakin tua umur pangkas tanaman teh, maka pucuk peko akan semakin sedikit dan pucuk burung semakin banyak. Hal tersebut menyebabkan potensi jumlah pucuk yang memenuhi syarat olah semakin sedikit, sehingga tidak menguntungkan perusahaan. Pucuk burung yang masih memenuhi syarat olah adalah pucuk burung dengan tiga daun muda $(B+3 \mathrm{M})$. Tabel pengamatan persentase pucuk burung dapat dilihat pada Tabel 2 . 
Tabel 2. Persentase pucuk burung sebelum pemangkasan

\begin{tabular}{|c|c|c|c|c|}
\hline Blok & Nomor kebun & $\mathrm{n}$ & Umur pangkas (tahun) & Persentase pucuk burung (\%) \\
\hline Taman & 15 & 11 & 4 & $92,85 \mathrm{a}$ \\
\hline Pemandangan 1 & 1 & 11 & 5 & $73,69 b$ \\
\hline Tanah Hijau & 8 & 11 & 5 & $84,96 \mathrm{ab}$ \\
\hline Rata-rata & & & & 83,83 \\
\hline
\end{tabular}

Keterangan: Angka yang diikuti huruf yang sama tidak berbeda nyata pada taraf $\alpha=5 \%$, n: jumlah tanaman contoh

Menurut Yilmaz et al. (2004), pucuk burung akan semakin meningkat pada tanaman tahun pangkas keempat. Menurut Sukasman (1988), pemangkasan dilakukan jika persentase pucuk burung $70 \%$. Persentase pucuk burung sebelum pemangkasan yang diterapkan di UP Tambi adalah > 70\%. Berdasarkan hasil pengamatan pada Tabel 2, persentase pucuk burung Blok Taman berbeda nyata dengan Blok Pemandangan 1 dan Blok Tanah Hijau, serta persentase pucuk burung Blok Pemandangan 1 berbeda nyata dengan Blok Tanah Hijau. Rata-rata persentase pucuk burung di ketiga blok $83,83 \%$. Berdasarkan hasil tersebut, tanaman teh sudah selayaknya dipangkas karena persentase pucuk burung yang lebih besar daripada standar.

\section{Produktivitas Tahun Sebelumnya (2016)}

Produktivitas tahun sebelumnya adalah kriteria sebelum dilakukan pemangkasan tanaman teh. Menurut Aryana (2016), pola produktivitas tanaman teh optimum pada tahun pangkas III dan menurun pada tahun pangkas IV. Pola produktivitas tanaman teh berdasarkan tahun pangkas 2016 pada blok-blok di UP Tambi menunjukkan perbedaan yang dapat dilihat pada Gambar 1.

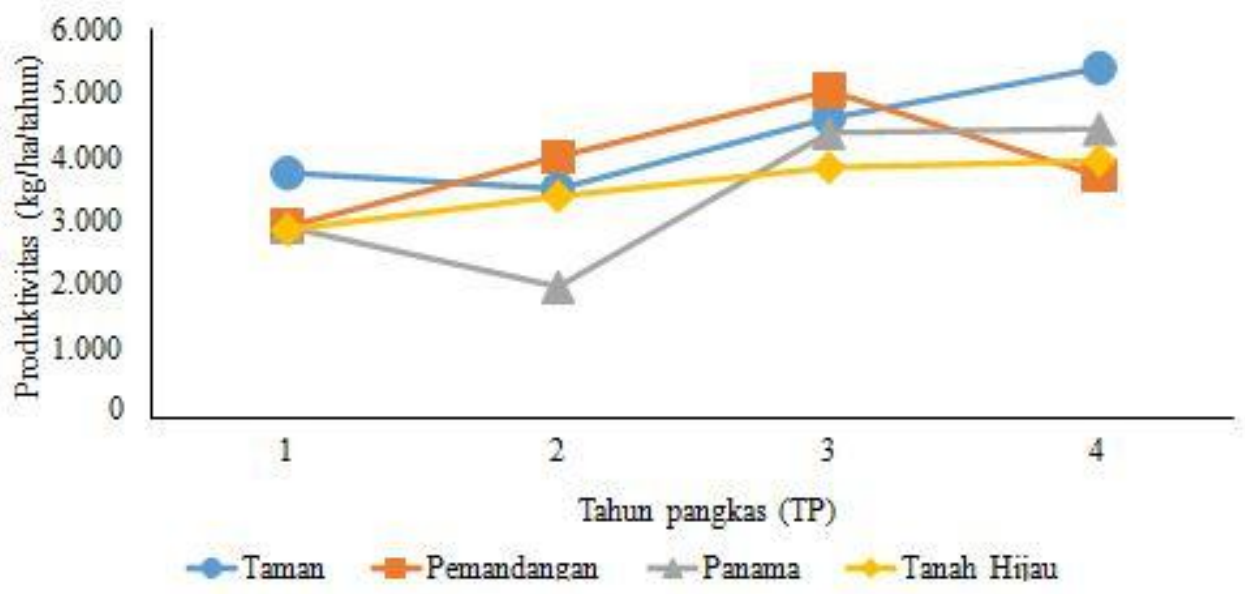

Gambar 1. Produktivitas blok-blok di UP Tambi berdasarkan tahun pangkas 2016

Produktivitas Blok Pemandangan yang memiliki ketinggian $1.700-2.150 \mathrm{~m}$ dpl sesuai dengan teori yaitu produktivitas TP I mulai meningkat, TP II meningkat lagi, TP III paling optimum, dan TP IV menurun. Produktivitas Blok Tanah Hijau yang memiliki ketinggian 1.225$1.490 \mathrm{~m} \mathrm{dpl}$ mengalami peningkatan seiring bertambahnya umur tahun pangkas. Blok Taman dan Blok Panama memiliki pola produktivitas yang sama, yaitu produktivitas TP I meningkat, TP II menurun, TP III meningkat lagi, dan TP IV paling optimum. Total produktivitas di keempat blok selama empat tahun berturut-turut adalah 16.810 Blok Taman, 15.239 Blok Pemandangan, 13.635 Blok Tanah Hijau, dan 13.305 kg ha-1 Blok Panama. Perbedaan pola produktivitas ini disebabkan oleh jenis klon, perlakuan saat pemeliharaan, pemetikan, dan iklim. Faktor-faktor yang mempengaruhi produktivitas adalah faktor genetik seperti klon (25\%), faktor lingkungan seperti iklim (15\%), teknik budidaya (35\%), dan manajerial (25\%) (Dalimoenthe, 2013). Selain itu, faktor-faktor yang mempengaruhi produktivitas yang lain adalah jumlah pemetik (Dahliani et al., 2006).

Klon yang ada di UP Tambi antara lain Gambung, TRI (Tea Research Institute), Seedling, dan klon lainnya. Klon Gambung memiliki potensi hasil yang tinggi daripada jenis klon yang lain dan tahan terhadap penyakit cacar. Klon Gambung 7 memiliki potensi hasil 5.800, Gambung 4 3.464, dan Gambung 34.247 kg ha-1 (PPTK, 1999). Kegiatan pemeliharaan meliputi pengendalian gulma, pengendalian hama penyakit, pemupukan, gosok lumut, porokan, dan rorak. Jika semua kegiatan pemeliharaan tersebut 
dilakukan denganbaik, maka produktivitas akan tinggi. Semakin banyak jumlah pemetik, maka pucuk yang dihasilkan akan semakin banyak, sehingga produktivitas akan tinggi.

Kriteria pemetikan adalah sebagai berikut: sistem petikan bersih menggunakan gunting petik, pucuk yang dipetik harus "manjing" terlebih dahulu, pucuk burung yang berada di atas bidang petik harus dipetik dan yang berada di bawah bidang petik harus ditinggal dahulu, dan bidang petik harus rata. Jika kriteria pemetikan tersebut terpenuhi dengan benar, maka produktivitas akan tinggi. Iklim meliputi suhu, kelembaban, curah hujan, ketinggian tempat, dan tanah. Iklim yang baik untuk pertumbuhan teh berkisar $13-25^{\circ} \mathrm{C}$, kelembaban $<70 \%$, curah hujan tahunan 2.000 $2.500 \mathrm{~mm}$, dan ketinggian tempat 200-2.000 m dpl. Tanah harus yang subur, mengandung bahan organik, $\mathrm{pH}$ berkisar 4,5-5,6, dan andisol (terletak di lereng gunung berapi) (Effendi et al., 2010).

\section{Pengamatan Saat Pemangkasan}

Kegiatan pengamatan saat pemangkasan meliputi : tinggi pangkasan, alat pangkas, tipe atau jenis pangkasan, persentase kerusakan cabang akibat pemangkasan, waktu pemangkasan, luas areal pangkasan, jumlah tenaga kerja dan kapasitas pemangkas, serta daur atau gilir pangkasan.

\section{Tinggi Pangkasan}

Tinggi pangkasan tanaman teh pada umumnya selalu naik. Unit Perkebunan Tambi menerapkan sistem pangkasan yang selalu naik, yaitu pangkasan pertama dilakukan pada ketinggian $45 \mathrm{~cm}$ dari permukaan tanah, kemudian dinaikkan $5 \mathrm{~cm}$ pada gilir pangkas berikutnya hingga ketinggian $60 \mathrm{~cm}$, turun lagi pada ketinggian $45 \mathrm{~cm}$ pada gilir pangkas berikutnya. Pengamatan tinggi pangkasan dapat dilihat pada Tabel 3.

Tabel 3. Tinggi pangkasan di Unit Perkebunan Tambi tahun 2017

\begin{tabular}{cccccc}
\hline Blok & $\begin{array}{c}\text { Nomor } \\
\text { Kebun }\end{array}$ & $\mathrm{n}$ & Umur Pangkas (tahun) & $\begin{array}{c}\text { Tinggi pangkasan } \\
\text { standar }(\mathrm{cm})\end{array}$ & $\begin{array}{c}\text { Tinggi } \\
\text { pangkasan }(\mathrm{cm})\end{array}$ \\
\hline Taman & 15 & 11 & 4 & 55 & $53,09 \pm 3,30$ tn \\
Pemandangan 1 & 1 & 11 & 5 & 55 & $48,77 \pm 4,80 * *$ \\
Tanah Hijau & 8 & 11 & 5 & 55 & $51,36 \pm 2,62 * *$ \\
\hline Rata-rata & & & & & $51,07 \pm 3,57$ \\
\hline
\end{tabular}

Keterangan: n: jumlah tanaman contoh, ${ }^{\text {tn: }}$ hasil uji-t pada baris yang sama menunjukkan hasil tidak berbeda nyata pada taraf $\alpha=5 \%$, **: hasil uji-t pada baris yang sama menunjukkan hasil berbeda nyata pada taraf $\alpha=$ $1 \%$.

Hasil pengamatan pada Tabel 3, menunjukkan bahwa tinggi pangkasan Blok Pemandangan 1 dan Blok Tanah Hijau sangat berbeda nyata dengan tinggi pangkasan standar yang diterapkan UP Tambi yaitu $55 \mathrm{~cm}$, sedangkan tinggi pangkasan Blok Taman tidak berbeda nyata dengan tinggi pangkasan standar. Perbedaan tersebut disebabkan oleh sistem upah borongan, tidak ada alat bantu ukur, serta kondisi dan topografi lahan. Sistem upah borongan menyebabkan pemangkas lebih memperhatikan kuantitas daripada kualitas hasil pangkasan, sehingga pemangkas tidak memperhatikan tinggi pangkasan standar. Pemangkas biasanya menggunakan lutut sebagai acuan tinggi pangkasan. Tidak ada alat bantu sebagai patokan tinggi pangkasan standar, sehingga tinggi pangkasan di kebun belum tepat dengan tinggi pangkasan standar yang ditetapkan. Kondisi lahan yang sulit atau topografi lahan yang bergelombang akan menghasilkan tinggi pangkasan yang beragam, sehingga tinggi pangkasan di kebun belum tepat dengan tinggi pangkasan standar yang ditetapkan.

\section{Alat Pangkas}

Alat pangkas yang digunakan di UP Tambi ada dua yaitu sabit dan mesin pangkas, tetapi yang sering digunakan adalah sabit pangkas. Hal tersebut dilakukan dengan tujuan untuk menghindari kerusakan cabang. Menurut Aryana (2016), kerusakan cabang dengan menggunakan sabit pangkas lebih rendah daripada menggunakan mesin pangkas. Menurut Sartika (2003), alat yang digunakan harus tajam, sehingga luka pangkas halus, batang tidak pecah atau rusak, dan produktivitas tinggi. Mesin pangkas hanya digunakan apabila tenaga pemangkas jumlahnya tidak memadai untuk melakukan pemangkasan secara manual, sebab semakin lama pemangkasan akan menunda pertumbuhan tunas, sehingga mengurangi produksi. Alat pemangkasan di Unit Perkebunan dapat dilihat pada Gambar 8.

Luka pangkas harus miring membentuk sudut $45^{\circ}$ dan menghadap ke dalam perdu. Luka harus membentuk sudut $45^{\circ}$ agar air yang menempel pada luka pangkas tidak menggenang yang menyebabkan luka menjadi busuk. Luka harus menghadap ke dalam perdu agar 
pertumbuhan tunas keluar atau ke samping lebih leluasa sehingga cepat menutup permukaan tanah supaya tidak terkena sinar matahari langsung.

\section{Tipe atau Jenis Pangkasan}

Tipe atau jenis pangkasan yang ada di UP Tambi ada lima yaitu pangkasan indung, bentuk, bersih (produksi), kepris, dan jambul (ajir). Tipe atau jenis pangkasan yang sering digunakan di UP Tambi adalah pangkasan bersih (produksi). Menurut Sukasman (1988), pangkasan bersih merupakan pemangkasan yang bertujuan untuk membentuk bidang pangkas rata, bagian tengah lebih rendah seperti mangkuk, dan cabangcabang kecil harus dibersihkan (diwiwil). Berdasarkan hasil pengamatan, tipe atau jenis pangkasan yang ada di kebun adalah pangkasan bersih. Pemilihan tipe/jenis pangkasan di kebun sesuai dengan tipe atau jenis pangkasan yang ada di UP Tambi. Pangkasan bersih dilakukan karena ketinggian tempat di UP Tambi $\geq 1.200 \mathrm{~m} \mathrm{dpl}$, dimana penyinaran matahari dan suhu tidak terlalu tinggi, sehingga tanaman dapat bertahan meskipun tidak ada daun yang disisakan setelah pemangkasan.

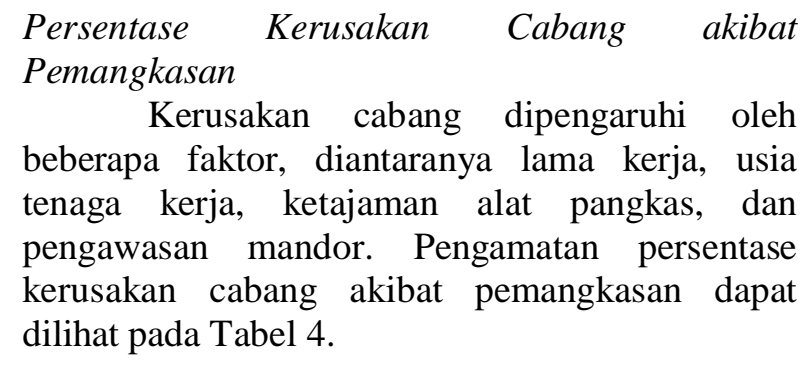

Tabel 4. Persentase kerusakan cabang akibat pemangkasan

\begin{tabular}{|c|c|c|c|}
\hline \multirow{2}{*}{$\begin{array}{c}\text { Lama kerja } \\
\text { (tahun) }\end{array}$} & \multirow{2}{*}{$\begin{array}{l}\text { Usia tenaga kerja } \\
\text { (tahun) }\end{array}$} & \multicolumn{2}{|c|}{ Kerusakan cabang } \\
\hline & & Diameter besar $(\geq 2 \mathrm{~cm})$ & Diameter kecil $(<2 \mathrm{~cm})$ \\
\hline 6 & 58 & 0 & 22,12 \\
\hline 5 & 50 & 0 & 26,82 \\
\hline 21 & 42 & 17,56 & 13,21 \\
\hline 21 & 38 & 13,77 & 14,85 \\
\hline 6 & 55 & 35,00 & 10,74 \\
\hline
\end{tabular}

Keterangan: tn: hasil uji-t pada kolom yang sama menunjukkan hasil tidak berbeda nyata pada taraf $\alpha=5 \%$

Menurut Aryana (2016), kerusakan cabang terkecil ada pada usia tenaga kerja $>50$ tahun dan lama kerja $>5$ tahun, sedangkan hasil pengamatan pada Tabel 7 menunjukkan hasil kerusakan cabang yang beragam pada usia tenaga kerja dan lama kerja yang sama. Hal tersebut disebabkan kurangnya pengawasan dari mandor dan ketajaman alat. Pengawasan mandor yang kurang menyebabkan tenaga kerja tidak melakukan pekerjaannya sesuai standar, sehingga kerusakan cabang yang dihasilkan tinggi. Alat pangkas yang tidak tajam menyebabkan tingginya kerusakan cabang yang dihasilkan. Rata-rata kerusakan cabang berdiameter kecil lebih tinggi daripada cabang berdiameter besar. Hal ini disebabkan pemangkasan pada cabang kecil dilakukan sekaligus dengan jumlah yang banyak dalam satu kali tebasan, sehingga hasil pangkasannya kurang rapi atau terdapat kerusakan cabang yang banyak.

\section{Waktu Pemangkasan}

Hasil pucuk mulai meningkat pada akhir musim hujan (Maret-April) karena sinar matahari mulai banyak, suhu udara meningkat, dan curah hujan mulai berkurang (Puslitbun, 1997). Selain itu, cabang yang dipangkas tidak terserang penyakit yang disebabkan curah hujan tinggi. Pemangkasan yang diterapkan di UP Tambi dibagi menjadi dua semester yaitu Semester I (Februari-Mei) dan Semester II (OktoberNovember). Realisasi pemangkasan pada blokblok di UP Tambi sesuai dengan waktu yang ditetapkan oleh UP Tambi. Pemangkasan pada Semester I dilakukan selama empat bulan, sedangkan Semester II selama dua bulan. Hal ini dikarenakan luas areal yang dipangkas pada Semester I lebih luas yaitu $70 \%$ dari luas total areal yang akan dipangkas seluruhnya dalam setahun.

\section{Luas Areal Pangkasan}

Luas areal pangkasan yang ditetapkan UP Tambi adalah 25\% dari luas TM dalam setahun. Pengamatan rencana luas areal pangkasan di UP Tambi tahun 2017 dapat dilihat pada Tabel 5. 
Tabel 5. Rencana luas areal pangkasan di Unit Perkebunan Tambi tahun 2017

\begin{tabular}{llccc}
\hline \multicolumn{1}{c}{ Blok (ha) } & \multicolumn{1}{c}{ Nomor kebun } & $\begin{array}{c}\text { Luas areal } \\
\text { pemangkasan }(\%)\end{array}$ & $\begin{array}{c}\text { Luas Tanaman } \\
\text { menghasilkan }\end{array}$ & $\begin{array}{c}\text { Persentasi areal } \\
\text { pangkasan }\end{array}$ \\
\hline Taman & $12,13,14,15$ & 15,85 & 58,69 & 27,01 \\
Pemandangan 1 & 1,15 & 10,81 & 38,91 & 27,78 \\
Pemandangan 2 & 10,11 & 7,32 & 29,93 & 24,46 \\
Tanah Hijau & $1,2,7$ & 17,62 & 65,20 & 27,02 \\
Panama & $8,10,11$ & 10,27 & 39,38 & 26,08 \\
\hline Jumlah & & 61,87 & 232,11 & - \\
Rata-rata & & 12,37 & 46,42 & 26,47 \\
\hline
\end{tabular}

Berdasarkan hasil pengamatan pada Tabel 5 , rata-rata persentase areal pangkasan melebihi luas areal pangkasan yang ditetapkan UP Tambi. Hal ini disebabkan oleh kondisi tanaman yang sudah mulai menurun, sehingga harus segera dipangkas agar memperbaiki produksi (dengan syarat kestabilan produksi tidak terganggu). Selain itu, kondisi tanaman yang terserang penyakit cacar harus segera dipangkas agar sumber penyakit tersebut tidak menyerang kebun yang lain dan untuk memperbaiki pucuk.

Pemangkasan di UP Tambi dilaksanakan dua semester yaitu $70 \%$ pada Semester I dan $30 \%$ pada Semester II. Luas areal pangkasan pada Semester I lebih luas karena agar pucuk dapat dipetik di Semester II dan mengejar target produksi di akhir tahun. Luas areal yang telah dipangkas hingga bulan Mei 2017 adalah 31,50 ha atau $72,73 \%$ dari total luas areal yang akan dipangkas pada Semester I. Berdasarkan hasil tersebut, maka masih kurang $27,27 \%$ areal yang belum dipangkas pada Semester I. Perbedaan luas areal pangkasan antara rencana dan realisasi ini terjadi karena terdapat beberapa nomor kebun yang disisakan untuk dipangkas pada akhir tahun, keseimbangan produksi, keadaan tanaman, ketersediaan dana dan tenaga kerja, serta adanya prioritas pekerjaan yang harus didahulukan.

\section{Jumlah Tenaga Kerja dan Kapasitas Pemangkas}

Tenaga pemangkas di UP Tambi merupakan tenaga kerja borongan. Tenaga kerja borongan lebih mengutamakan kuantitas daripada kualitas. Kapasitas standar merupakan kemampuan yang harus dicapai seorang pemangkas. Kapasitas standar yang ditetapkan di UP Tambi adalah 0,04 ha $\mathrm{HK}^{-1}$. Pengamatan jumlah tenaga kerja dan kapasitas pemangkas di UP Tambi tahun 2017 dapat dilihat pada Tabel 6.

Tabel 6. Jumlah tenaga dan kapasitas pemangkas di Unit Perkebunan Tambi tahun 2017

\begin{tabular}{lcrrrc}
\hline \multicolumn{1}{c}{ Blok } & $\begin{array}{c}\text { Luas Pangkasan (ha } \\
\text { hari }^{-1} \text { ) }\end{array}$ & \multicolumn{2}{c}{$\begin{array}{l}\text { Jumlah tenaga pemangkas (HK) } \\
\text { Standar* }\end{array}$} & \multicolumn{2}{c}{ Kapasitas pemangkas (ha HK $^{-1}$ ) } \\
Standar & Riil* \\
\hline Taman & 0,08 & 2 & 2 & 0,04 & 0,04 \\
Pemandangan 1 & 0,13 & 3 & 1 & 0,04 & 0,13 \\
Pemandangan 2 & 0,14 & 4 & 2 & 0,04 & 0,07 \\
Tanah Hijau & 0,16 & 4 & 2 & 0,04 & 0,08 \\
Panama & 0,16 & 4 & 3 & 0,04 & 0,05 \\
\hline Jumlah & 0,66 & 17 & 10 & - & - \\
Rata-rata & 0,13 & 3 & 2 & 0,04 & 0,07 \\
\hline
\end{tabular}

Keterangan: HK: hari kerja, *: hasil didapat dari perhitungan rumus

Sumber : Laporan mandor (2017)

Berdasarkan hasil pengamatan pada Tabel 6, jumlah tenaga pemangkas standar di UP Tambi adalah 17 orang, tetapi riilnya hanya 10 orang. Perbedaan ini menunjukkan bahwa di UP Tambi kekurangan tenaga kerja pangkas. Hal tersebut disebabkan oleh semakin sedikitnya orang yang bersedia menjadi tenaga pangkas. Oleh karena itu, tenaga pangkas harus memiliki keterampilan yang baik agar dapat mengefisiensi jumlah tenaga pangkas. Berdasarkan hasil pengamatan pada Tabel 6, hanya kapasitas Blok Taman yang sesuai dengan kapasitas standar. Blok yang lainnya melebihi kapasitas standar. Hal tersebut terjadi karena jumlah tenaga pangkas riilnya lebih sedikit daripada jumlah tenaga pangkas standarnya (kekurangan tenaga pemangkas). Semakin tinggi kapasitas pemangkasnya, maka kegiatan pemangkasan akan cepat selesai sehingga dapat mengefisienkan jumlah tenaga pemangkas. 


\section{Daur atau Gilir Pangkasan}

Daur atau gilir pangkas adalah interval antara pemangkasan terdahulu dengan pemangkasan berikutnya dan biasanya dinyatakan dalam tahun. Gilir pangkas dipengaruhi oleh kondisi tanaman, produktivitas tanaman, dan ketinggian tempat (PPTK, 2006). Semakin baik kondisi tanaman dan produktivitas tanaman, maka semakin lama gilir pangkasnya. Semakin tinggi tempat dari permukaan laut, maka gilir pangkasnya akan semakin panjang. Pengamatan gilir pangkas di UP Tambi tahun 2017 dapat dilihat pada Tabel 7.

Tabel 7. Gilir pangkas di Unit Perkebunan Tambi tahun 2017

\begin{tabular}{lccccccc}
\hline Blok & $\begin{array}{c}\text { Nomor } \\
\text { kebun }\end{array}$ & $\begin{array}{c}\text { Luas } \\
\text { (ha) }\end{array}$ & $\begin{array}{c}\text { Tinggi tempat } \\
\text { dpl) }\end{array}$ & \multicolumn{2}{c}{$\begin{array}{c}\text { Waktu pemangkasan } \\
\text { (tahun) }\end{array}$} & $\begin{array}{c}\text { Gilir } \\
\text { pangkas } \\
\text { (tahun) }\end{array}$ & $\begin{array}{c}\text { Produktivitas } \\
\text { (kg ha }^{-1} \\
\left.\text { tahun }^{-1}\right)\end{array}$ \\
\hline Taman & 12 & 5,07 & $1.415-1.600$ & 2013 & 2017 & 4 & 5.298 \\
& 15 & 2,38 & $1.415-1.600$ & 2013 & 2017 & 4 & 4.121 \\
Pemandangan 1 & 1 & 3,98 & $1.700-2.150$ & 2012 & 2017 & 5 & 5.407 \\
Pemandangan 2 & 10 & 4,26 & $1.700-2.150$ & 2012 & 2017 & 5 & 3.636 \\
Tanah Hijau & 8 & 4,75 & $1.225-1.490$ & 2012 & 2017 & 5 & 2.717 \\
Panama & 1 & 6,87 & $1.260-1.525$ & 2012 & 2017 & 5 & 4.182 \\
& 4 & 4,19 & $1.260-1.525$ & 2012 & 2017 & 5 & 5.158 \\
\hline
\end{tabular}

Berdasarkan ketinggian tempat daerah pertumbuhan teh, pedoman umum panjang daur pangkasan ada tiga, yaitu: (1) daerah rendah (< $800 \mathrm{~m} \mathrm{dpl}$ ) daur pangkasnya berkisar 2-3 tahun, (2) daerah sedang (800-1.200 m dpl) daur pangkasnya antara 3-4 tahun, dan (3) daerah tinggi (> $1.200 \mathrm{~m} \mathrm{dpl}$ ) daur pangkasnya 4-5 tahun (Pusat Penelitian Teh dan Kina, 2006). UP Tambi menerapkan daur/gilir pangkas 4-5 tahun. Berdasarkan hasil pengamatan pada Tabel 8, gilir pangkas kelima blok di UP Tambi telah sesuai dengan standar.

\section{Pengamatan Setelah Pemangkasan}

Pertumbuhan Tunas Baru. Pertumbuhan tunas baru adalah kriteria keberhasilan pemangkasan tanaman teh. Pertumbuhan tunas dipengaruhi oleh ketinggian tempat, umur tanaman, klon, kesuburan tanah, dan intensitas pohon pelindung. Pengamatan pertumbuhan tunas baru pada cabang berdiameter $<2 \mathrm{~cm}$ dan cabang berdiameter $\geq 2$ $\mathrm{cm}$ dapat dilihat pada Gambar 2.

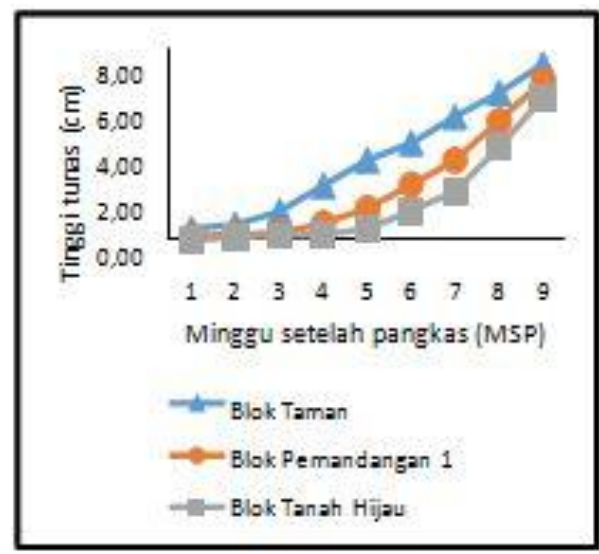

(a)

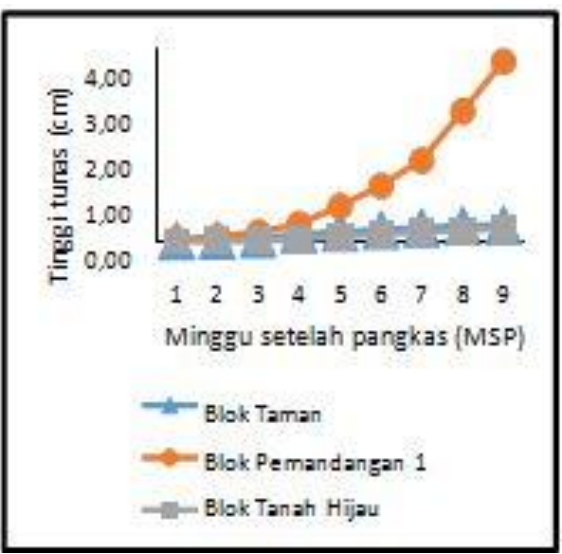

(b)

Gambar 2. Pertumbuhan tunas pada cabang berdiameter $<2 \mathrm{~cm}$ dan $\geq 2 \mathrm{~cm}$ di Blok Taman, Blok Pemandangan 1, dan Blok Tanah Hijau

Berdasarkan hasil pengamatan pada Gambar 2, pertumbuhan tunas cabang berdiameter kecil dan cabang berdiameter besar pada ketiga blok terus meningkat hingga 9 minggu setelah pangkas (MSP). Tinggi tunas cabang berdiameter kecil di Blok Taman adalah 7,31 cm, Blok
Pemandangan 1 6,62 cm, dan Blok Tanah Hijau $5,89 \mathrm{~cm}$. Tinggi tunas cabang berdiameter besar di Blok Taman adalah 0,34 cm, Blok Pemandangan 13,72 cm, dan Blok Tanah Hijau $0,28 \mathrm{~cm}$. Tinggi tunas cabang berdiameter kecil dan berdiameter besar menunjukkan hasil yang 
beragam. Hal ini disebabkan ketinggian tempat, intensitas cahaya, umur tanaman, klon, intensitas pohon pelindung, dan kesuburan tanah yang berbeda.

Semakin tinggi letak kebun dari permukaan laut, maka pertumbuhan tanaman teh akan semakin lambat. Hal tersebut disebabkan intensitas cahaya dan suhu rendah, serta kelembaban tinggi, sehingga rentan serangan penyakit cacar daun teh (PPTK, 2006). Semakin tua umur tanaman, maka semakin lama pertumbuhan tunasnya. Hal tersebut disebabkan dormansi tunas semakin kuat (Sukasman, 1988). Klon Gambung 4 memiliki potensi hasil yang lebih tinggi (3.464 $\mathrm{kg} \mathrm{ha}^{-1}$ ) daripada Seedling (PPTK, 1999). Intensitas pohon pelindung yang rapat menyebabakan tanaman tidak mendapat sinar matahari langsung. Penyinaran yang kurang menyebabkan kelembaban tinggi, sehingga banyak tanaman yang terserang cacar daun teh. Semakin subur tanah, maka pertumbuhan tunas akan semakin cepat. Hal tersebut disebabkan unsur-unsur hara yang terkandung di dalam tanah banyak, sehingga membantu pertumbuhan tunas.

Pertumbuhan tunas baru pada cabang berdiameter kecil $(<2 \mathrm{~cm})$ lebih cepat daripada cabang berdiameter besar $(\geq 2 \mathrm{~cm})$. Hal tersebut disebabkan unsur hara akan lebih mudah terserap pada cabang berdiameter kecil daripada diameter besar. Selain itu, cabang berdiameter kecil artinya cabang tersebut masih muda daripada cabang berdiameter besar (cabang yang sudah tua). Semakin muda cabang, maka cadangan pati masih banyak sehingga pertumbuhan tunas cabang berdiameter kecil lebih cepat tumbuh daripada cabang berdiameter besar.

\section{KESIMPULAN}

Hasil pengamatan sebelum pemangkasan telah sesuai dengan literatur dan RKAP UP Tambi. Hasil pengamatan tersebut antara lain tinggi tanaman sebelum dipangkas 94,55 cm, diameter bidang petik $105,99 \mathrm{~cm}$, persentase pucuk burung $83,27 \%$, dan pola produktivitas tanaman yang berbeda-beda di ke-4 blok. Luas areal pangkasan hingga bulan Mei 2017 adalah 31,50 ha $(72,73 \%)$, sehingga masih terdapat $27,27 \%$ target luas areal pangkasan yang harus dipangkas pada Semester I. Pertumbuhan tunas cabang berdiameter kecil $(<2 \mathrm{~cm})$ lebih tinggi daripada cabang berdiameter besar $(\geq 2 \mathrm{~cm})$. Pemeliharaan setelah pemangkasan perlu dilakukan agar tunas-tunas yang tumbuh banyak.

\section{DAFTAR PUSTAKA}

Aryana. 2016. Pengelolaan pemangkasan tanaman teh (Camellia sinensis (L.) O. Kuntze) dalam meningkatkan produktivitas di Unit Tambi, PT Perkebunan Tambi, Kabupaten Wonosobo, Jawa Tengah. Skripsi. Institut Pertanian Bogor. Bogor.

Dahliani, L., Sudradjat, H.S. Arifin. 2006. Analisis pencapaian produktivitas pemetikan pucuk sebagai dampak agrowisata di Kebun Teh Gunung Mas, Bogor. Buletin Agronomi. 34(3):188193.

Dalimoenthe, S.L. 2013. Pemetikan dan Pemangkasan. Pusat Penelitian Perkebunan Gambung, Bandung.

Effendi, D.S., M. Syakir, M. Yusron. dan Wiratno. 2010. Budi Daya dan Pascapanen Teh. Pusat Penelitian dan Pengembangan Perkebunan, Bogor.

Enomoto, R. 2013. Petunjuk teknis tanaman teh untuk petani kecil di Indonesia. Rainforest Alliance, Indonesia.

Helmayanti, H. 2011. Analisis beban kerja pada aktivitas pemetikan teh secara manual di PT Perkebunan Nusantara VIII, Kebun Gunung Mas, Cisarua, Bogor, Jawa Barat. Skripsi. Institut Pertanian Bogor. Bogor.

Martono, B., R.T. Setiyono. 2014. Skrining fitokimia enam genotipe teh. Jurnal Tanaman Industri dan Penyegar. 1(2):63-68.

[PDSIP] Pusat Data dan Sistem Informasi Pertanian. 2015. Outlook Teh. Sekretariat Jenderal Kementerian Pertanian, Jakarta.

[Puslitkaret] Pusat Penelitian Karet. 2016. Hasil Analisis Tanah. Pusat Penelitian Karet. Balai Penelitian Getas, Salatiga.

[Puslitbun] Pusat Penelitian Perkebunan. 1997. Petunjuk Kultur Teknik Tanaman Teh. Ed ke-1. Asosiasi Penelitian dan Pengembangan Perkebunan Indonesia, Bandung.

[PPTK] Pusat Penelitian Teh dan Kina. 1999. Pelepasan Klon Teh Seri PPS 1, PPS 2, MPS 5, MPS 6, MPS 7, dan GPPS 1. 
Pusat Penelitian Teh dan Kina Gambung, Bandung.

.2006

Petunjuk Kultur Teknis Tanaman Teh. Ed ke-3. Pusat Penelitian Teh dan Kina Gambung, Bandung.

Riduwan, Sunarto. 2011. Pengantar Statistika untuk Penelitian: Pendidikan, Sosial, Komunikasi, Ekonomi, dan Bisnis. Alfabeta, Bandung.

Sartika, D. 2003. Pengelolaan pemangkasan tanaman teh (Camellia sinensis (L.) O. Kuntze) di Perkebunan Rumpun Kemuning PT. Astra Agro Lestari Tbk, Karang Anyar, Jawa Tengah. Skripsi. Institut Pertanian Bogor. Bogor.

Setyamidjaja, D. 2000. Teh, Budi Daya, dan Pengolahan Pascapanen. Kanisius, Yogyakarta.
[SPI] Statistik Perkebunan Indonesia. 2014. Teh. Direktorat Jenderal Perkebunan, Jakarta.

Sukasman. 1988. Pemangkasan pada tanaman teh menghasilkan. Prosiding. Seminar Pemangkasan Teh. Gambung, Bandung, 12 Desember 1988.

Supriadi, H., D.N. Rokhmah. 2014. Teknologi adaptasi untuk mengatasi perubahan iklim pada tanaman teh. SIRINOV. 2(3):147156.

Yilmaz, G., N. Kandemir, K. Kinalioglu. 2004. Effects of different pruning intervals on fresh shoot yield and some quality properties of tea (Camellia sinensis (L.) O. Kuntze) in Turkey. Pakistan Journal of Biological Sciences. 7(7):1208-1212. 